\title{
Building a curriculum for bioentrepreneurs
}

\author{
Lynn Johnson Langer
}

How best to educate scientists about the business of biotech?

\footnotetext{
Therater
}

he process of moving biotechnologies out of academia and into industry remains a mystery to many scientists. What's more, knowledge of the commercial sector in academic circles can lag many years behind present business practice, especially when industry models are constantly evolving. Most life science researchers simply are not trained in the complexities of commercialization. Properly educating more researchers to understand entrepreneurship and have the skill sets needed to succeed in the commercial world is of tremendous importance for translating discoveries into products, building companies and also providing the knowledgeable recruits that industry wants to hire.

As an educator with 20 years of experience in teaching graduate students about developments in the biotech industry, I have learnt that successful education requires both good educators running your classes and a comprehensive program supporting them. In the following article, I describe my experience leading a bioentrepreneurship program at Johns Hopkins University (Baltimore, MD), provide tips on recruiting and retaining effective faculty, describe the ways of organizing different curricula to suit different graduate student needs and intersect with different arms of the university, and finish by discussing some of the ways in which the effectiveness of these courses can be measured.

\section{Making educators}

I started teaching at Johns Hopkins as an adjunct in 1995, and since 2001 I've been a full-time faculty member in the university's

Lynn Johnson Langer is Director, Enterprise \& Regulatory Science Programs, Center for Biotechnology Education, Advanced Academic Programs, The Johns Hopkins University, Rockville, Maryland, USA.

e-mail: ljlanger@jhu.edu
Krieger School of Arts and Sciences, where I currently run the graduate education programs in the enterprise and regulation of biotech. This experience has taught me that proper biotech education requires a trifecta of talent: science knowledge, business acumen and the ability to teach entrepreneurship to scientists. The true measure of a good faculty member for a bioentrepreneurship course is that he or she can engage students over the defined content but also teach them to think outside the curriculum and create new concepts and ideas. Good faculty members also know how to create learning exercises and assessments that lead students to desire more knowledge on a topic.

I admit these talents are difficult to find in the wild, though certainly each skill can be acquired. Recruiting instructors for physical classrooms is harder if you are not located in a biotech hub, but many of our programs are now offered online, so we have faculty from around the world leading these virtual classes. To support new hires, we offer faculty development workshops, both on-site and online, to train staff in the pedagogy of teaching and learning as well as keep them abreast of new technology. Mostly we've staffed our program through references from our existing faculty and from our students. (After meeting a potential hire, I leave it to them to reach out-this shows me that they are serious and have initiative.) We're also lucky enough to have high visibility for our program, which means potential faculty members often approach us. Our part-time instructors are leaders in the biotech industry and their specific fields: we have CEOs, lab chiefs, government experts and more as faculty members. They all have advanced degrees, and we train them in the skills needed to effectively deliver the content.

Once we think we have a potential hire, we treat them as any other employer does: we check the credentials and references of applicants, and we talk to them to see if they have the right personality to engage students, either online or in a physical classroom. If we find mutual interest, we suggest that they attend a class or guest lecture to get a sense of what will be required. If they remain interested, we then offer training and a mentor to help them learn teaching skills.

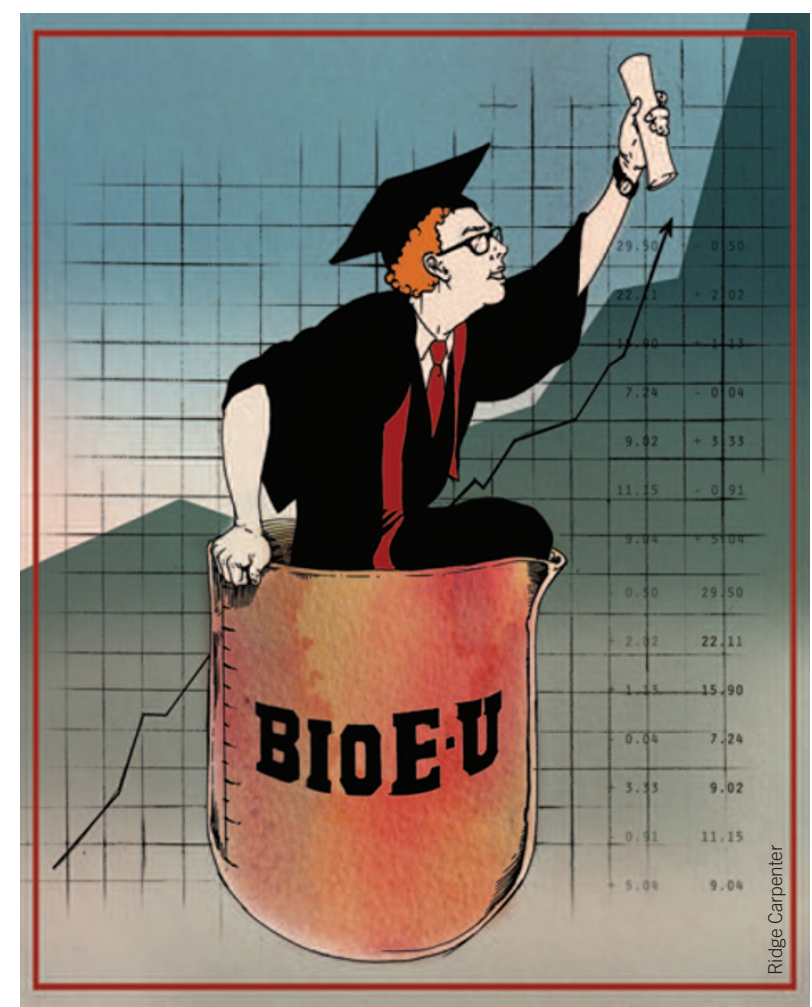


Once they are hired, we keep tabs on our current instructors through our students. Our evaluations are administered midway through a course and again at the end. Students are asked questions about the quality of the instruction and the course itself. For instance, students tell us if the instructor encouraged participation in the class and if the assignments were effective ways to learn the material. The questionnaire does help encourage feedback, but we find we hear from our students regularly anyway, as they are adults, and adult students are vocal.

When we have made the rare bad hire, it's easy enough to rectify: many teachers are brought on specifically for a course, and if their performance isn't satisfactory, we simply do not rehire them. Conversely, if instructors begin to teach multiple courses and consistently receive strong evaluations and participate in their own development, it's possible that we will hire them on a permanent basis. (Many of our faculty are adjunct; a recent study discussed in the Chronicle of Higher Education shows that adjuncts tend to make better teachers, and I've found that adjunct faculty have the advantage that they rarely have an agenda beyond simply teaching ${ }^{1}$.)

But that's Johns Hopkins; our program has been in place for years. If you have a newer program or are facing a quick build-out, the best way to grow your instructor base is to attend conferences and meetings where you can promote your programs. Another way is to actively put the word out through your own networks. We go to national meetings to network extensively. For example, I recently attended an open house at the US National Institutes of Health (Bethesda, MD), where I met a director from the National Center for Biotechnology Information. He was interested in our program and has since connected with our bioinformatics group, inquiring about teaching for us. These types of interactions happen only if you're out there and being proactive.

\section{A roof over their heads}

Even excellent teachers need to be supported by a robust program. The main, overall goals of these programs should be to ready students to bring bio-discoveries all the way to market, so how to start a company is just the beginning of any instruction.

There are many programs in the United States and abroad (Box 1), but at Johns Hopkins, we have two master's programs and a certificate that focuses on bioentrepreneurship (Box 2).

The first program is the Masters in Biotechnology Enterprise and Entrepreneurship (MBEE) offered by the Johns Hopkins University Center for Biotechnology Education. Most students in the MBEE program have a background in cell biology and biochemistry. (For those few who don't, we offer a prerequisite course, Foundations in Bioscience.) Students who complete the MBEE program should be able to:

- Formulate strategies that reflect the interdisciplinary nature of the biotech industry in the areas of science, regulation and business

- Formulate and carry out appropriate leadership and management strategies to achieve company goals and objectives

- Create financial and funding strategies for organizational success under various economic situations

- Demonstrate principles of human interrelationships between research, design and development activities, with emphasis upon principles of communication

- Demonstrate a working knowledge of the various steps in the development of a pharmaceutical, from its inception as intellectual property to scale-up to the final product

- Create appropriate marketing strategies aimed at organizational goals and objectives

- Formulate product launch strategies in the United States and internationally that reflect ongoing changes in the regulation of the product approval and marketing process

- Solve organizational problems arising from a legal and technology framework

- Identify, evaluate and assess risks and payoffs in monetary and non-monetary terms

- Develop a structure to develop financial strategy and tactics and understanding business planning.

The MBEE program teaches students not only to start up new companies but also to successfully sustain them through their growth cycle. Our second graduate program, the MS/MBA, is slightly different in that it integrates science and business, enabling students to be effective leaders in this industry. This program is intended for people who need to deepen their understanding of the science of biotech and who also want to move into the business side. The Master of Science is a science-based program in which students broaden their understanding of biochemistry, cell biology and molecular biology. The MBA is offered from the Johns Hopkins Carey Business School and is part of their 'flex MBA' program. Students work on both degrees at the same time. On completion of this jointdegree program, students will be able to:

- Apply the core principles of science and business to the biotech industry

- Fluently speak the language of science and business

- Ask the right questions of scientists and business people on critical issues facing their organizations

- Identify, evaluate, and act on scientific and business opportunities that arise in the field.

We also offer a Certificate in Biotech Enterprise. This was developed for scientists who don't want to complete a full degree but want to understand biotech fundamentals. Often students in the certificate program

\section{Box 1 Selected schools with bioentrepreneurship programs}

Carnegie Mellon University (Pittsburgh, PA)

Case Western Reserve University (Cleveland, $\mathrm{OH}$ )

Columbia University (New York, NY)

Copenhagen Business School (Frederiksberg, Denmark)

Fuqua School of Business, Duke University (Durham, NC)

George Washington University (Washington, DC)

Industrial College of the Armed Forces (Washington, DC)

Johns Hopkins University (Baltimore, MD)

Karolinska Institutet (Stockholm, Sweden)

Keck Graduate Institute of Applied Life Sciences (Claremont, CA)

London Business School Sussex Place (London, UK)

Spears School of Business (Stillwater, OK)

The Ohio State University (Columbus, $\mathrm{OH}$ )
Universidad Nacional de Rosario (Santa Fe, Argentina)

University of California, Davis

University of California, Irvine

University of Colorado, Boulder

University of Colorado, Denver

University of Denver (Denver, CO)

University of Houston (Houston, TX)

University of New South Wales (Sydney, Australia)

University of Pretoria (Pretoria, South Africa)

University of San Francisco (San Francisco, CA)

University of South Florida (Tampa, FL)

University of Valencia Science (Valencia, Spain)

Wharton School, University of Pennsylvania (Philadelphia, PA) 


\section{Box 2 Internships}

Internships, practicums and capstones provide students with opportunities for realworld experiences. For obvious reasons, it is easier to find internships in biotech hubs, where companies often look for additional staff or have short-term projects needing temporary help, but no matter where the entrepreneurship program is located, there are opportunities.

At Johns Hopkins's Center for Biotech Education, students often work with biotech companies to solve problems or create business and/or marketing plans as part of their course work. Johns Hopkins also offers independent projects, in which students receive academic credit but no pay. Some students do find internships as well. Pay for official internships can vary from $\$ 15 /$ hour all the way up to $\$ 5,000 /$ month, although that high end was reached just once, when students were hired to work on Wall Street.

At Case Western Reserve University in Cleveland, $\mathrm{OH}$, opportunities include interning at startups or younger companies evaluating their technology, with academics, or in biotech incubators (Ohio has at least six). Internships are also available in university or hospital technology transfer offices. Companies offering internships can access funding from Choose Ohio First to help offset the costs of employing interns. Interns earn around $\$ 18$ an hour and work between 20 and 40 hours a week. They are often later hired for permanent jobs by the company they interned for.

Outside the United States, the BioBusiness and Innovation Program at Copenhagen Business School offers two-and-a-half-month unpaid internships in Denmark's various life science companies. Students analyze a topic of current strategic interest to the host company - perhaps new product features or market segments - and deliver results in a report that is also applied toward their academic requirements.

transfer into the full degree. On completion of the certificate, students will be able to:

- Formulate and implement strategies within the interdisciplinary functional areas of the biotech enterprise

- Define and expand their professional role in a biotechnology enterprise through completion of a variety of required and elective courses

- Demonstrate principles of human interrelationships to research, design and development activities.

There is debate in the field as to whether biotech education courses should be housed in the business school, with the sciences or perhaps in their own silo. In the case of Johns Hopkins, the school created the Center for Biotechnology Education in the Krieger School of Arts and Sciences because of a belief that biotechnology and bioentrepreneurship are multidisciplinary. The university also offers a joint program with the Carey Business School for an MS Biotechnology/MBA, in which students pursue two degrees at once, but in many cases, entrepreneurship programs are separate from business schools. The Sloan School of Management at the Massachusetts Institute of Technology (http://mitsloan.mit.edu/) is a stand-alone example.

In my experience, many students prefer a targeted degree that incorporates a specific understanding of the relatonship between science and business. This means the fit with a business school is not always a good one unless there is a science component included. All students in our MBEE program take courses that require an understanding of biochemistry and cell biology and of how the science informs the biological underpinnings of discovery through manufacturing, regulation and commercialization. We feel that the very innovative nature of these programs derives from a variety of sources and ideas, and our fit inside the Krieger School of Arts and Sciences is aligned with that belief.

A side note here: bioentrepreneurship courses can benefit from the rise of virtual classrooms. Although the common view of online education is currently slanted by the recent evolution of Massive Open Online Courses that accept all students and have a dismal completion rate, the online courses in the Johns Hopkins Center for Biotechnology Education are capped at 16-18 students per section and are taught in most cases by the same faculty who teach in physical classrooms. The courses are asynchronous and highly interactive; and as biotech companies become increasingly global, the use of ubiquitous technology such as phone and video conferencing, e-mail, tweeting and texting for virtual education mimics the realworld experience of doing business.

\section{Shaping the future}

Because bioentrepreneurship education is still nascent, as a group we need to determine core competencies that programs internationally agree are necessary to provide. Toward this end, in 2012, our Center for Biotechnology Education hosted the first International BioEntrepreneurship Education Consortium (BEC) at Johns Hopkins (it was held at Columbia University in 2013 and the University of Colorado, Denver, in 2014). But in truth the industry is still too new to determine the success of the programs, so part of the goal of the $\mathrm{BEC}$ will be to provide guidelines for measuring the success of these programs, and once we have defined the core competencies for bioentrepreneurship, we will be better positioned to examine and rank them. As a group, university bioentrepreneurship programs are creating the Society of International Bioentrepreneurship Education and Research (SIBER) to help frame the discussion surrounding core competencies and legitimacy of education in bioentrepreneurship.

This goal is complicated by the fact that many scientists around the world still view the business world as distasteful or even as a cop-out - a side show to their original desire to help humanity through research. But in the twenty-first century, is there really room for such prejudice when public research budgets are shrinking, fewer tenured faculty positions are available and any investigator seeking to turn a research discovery into a product needs to call on development expertise from industry to have any possibility of reaching the market?

There is hope of incorporating entrepreneurship into undergraduate degree programs, but we need to engage our young people as early as middle school to consider the intersection of science and business as an exciting career possibility and a way to benefit the human condition. A global network of bioentrepreneurship programs is an important step in that direction.

\section{COMPETING FINANCIAL INTERESTS}

The author declares no competing financial interests.

1. Berret, D. Adjuncts are better teachers than tenured professors, study finds. Chron. Higher Educ. (9 September 2013). 